\title{
Characterization of the role for cadherin 6 in the regulation of human endometrial receptivity
}

\author{
Wei Zhou ${ }^{1,2}$ (D) Leilani Santos ${ }^{1,2}$ and Evdokia Dimitriadis ${ }^{12^{*}}$ (D)
}

\begin{abstract}
Background: The endometrial luminal epithelium is the first point of attachment of embryos during implantation. Failure of embryos to firmly adhere results in implantation failure and infertility. A receptive endometrial luminal epithelium is achieved through the expression of adhesion molecules in the mid-secretory phase and is a requirement for implantation. Cadherin $6(\mathrm{CDH} 6)$ is an adhesion molecule localizing to the endometrial luminal epithelial cell surface in the mid-secretory/receptive phase and knockdown of CDH6 in the Ishikawa cells (receptive endometrial epithelial cell line) compromises cell integrity. However, there are no studies investigating the role of $\mathrm{CDH} 6$ on receptivity and infertility. This study aimed to investigate whether $\mathrm{CDH} 6$ is dysregulated in the endometrium of women with infertility during the receptive window and the effect of $\mathrm{CDH} 6$ on endometrial adhesion and receptivity.
\end{abstract}

Methods: The expression and the localization of $\mathrm{CDH} 6$ in the human endometrium were determined by immunohistochemistry. Ishikawa cells were used to investigate the functional consequences of CDH6 knockdown on endometrial adhesive capacity to HTR8/SVneo (trophoblast cell line) spheroids in vitro. CDH6 knockdown was assessed by qPCR and immunoblotting. After $\mathrm{CDH} 6$ knockdown, the expression of type II cadherin family members and $\mathrm{CDH} 6$ functional partners were assessed by qPCR. Two-tailed unpaired student's t-test or one-way ANOVA as appropriate were used for statistical analysis with a significance threshold of $P<0.05$.

Results: A significant reduction of $\mathrm{CDH} 6$ immunolocalization was recorded in the luminal and glandular epithelium of endometrium from women with infertility $(P<0.05)$ compared to fertile group respective cellular compartments in the mid-secretory phase. Functional analysis using Ishikawa cells demonstrated that knockdown of CDH6 (treated with $50 \mathrm{nM} C D H 6$ siRNA) significantly reduced epithelial adhesive capacity $(P<0.05)$ to HTR8/SVneo spheroids compared to control and other type II cadherin family members likely failed to compensate for the loss of CDH6. The expression levels of $\mathrm{CDH} 6$ functional partners, catenin family members were not changed after $\mathrm{CDH} 6$ knockdown in Ishikawa cells.

(Continued on next page)

\footnotetext{
* Correspondence: eva.dimitriadis@unimelb.edu.au

'Department of Obstetrics and Gynaecology, University of Melbourne,

Parkville, Victoria 3010, Australia

${ }^{2}$ Gynaecology Research Centre, Royal Women's Hospital, Parkville, Victoria

3052, Australia
}

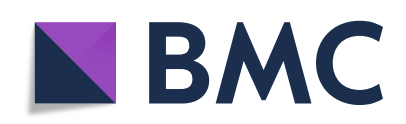

(c) The Author(s). 2020 Open Access This article is licensed under a Creative Commons Attribution 4.0 International License, which permits use, sharing, adaptation, distribution and reproduction in any medium or format, as long as you give appropriate credit to the original author(s) and the source, provide a link to the Creative Commons licence, and indicate if changes were made. The images or other third party material in this article are included in the article's Creative Commons licence, unless indicated otherwise in a credit line to the material. If material is not included in the article's Creative Commons licence and your intended use is not permitted by statutory regulation or exceeds the permitted use, you will need to obtain permission directly from the copyright holder. To view a copy of this licence, visit http://creativecommons.org/licenses/by/4.0/. The Creative Commons Public Domain Dedication waiver (http://creativecommons.org/publicdomain/zero/1.0/) applies to the data made available in this article, unless otherwise stated in a credit line to the data. 
(Continued from previous page)

Conclusion: Together, our data revealed that $\mathrm{CDH} 6$ was dysregulated in the endometrium from women with infertility and altered Ishikawa cell adhesive capacity. Our study supports a role for $\mathrm{CDH} 6$ in regulating endometrial adhesion and implantation.

Keywords: Endometrial receptivity, Adhesive molecules, CDH6, Embryo implantation, Endometrial epithelial cell, Trophoblast cell

\section{Background}

Infertility affects a staggering 1 in 10 couples of reproductive age worldwide [1]. A failure of embryo implantation is a major cause of infertility. Human embryo implantation starts with the initial contact and adhesion between a blastocyst and the endometrial luminal epithelium [2,3]. The inadequate adhesive capacity of the endometrial luminal epithelium leads to inadequate embryo attachment and implantation failure. Defective endometrial adhesion is one of the leading causes of implantation failure and infertility $[4,5]$ while the mechanisms contributing to this remain poorly defined.

The endometrial luminal epithelium is only receptive to an implanting blastocyst within a narrow window of $2-4$ days in the mid-secretory phase [6,7]. Within this time frame, the luminal epithelium undergoes a complex series of changes including the altered expression of adhesive molecules such as cadherins to ensure embryos attach and firmly adhere to initiate implantation [8]. Cadherins comprise a large family of cell adhesion molecules consisting of more than eighty family members [9] and are key regulators of cell adhesion, sorting and invasion [10]. Structurally, cadherins contain repeated extracellular domains that interact generally in a homophilic manner to their own family members to mediate cellcell interactions, whereas their cytoplasmic regions are associated with a wide range of proteins including cytoskeletal regulators, enzymes and transcriptional factors which endow them with diverse downstream functional capabilities [10].

A previous high-density microarray screen on human endometrium reveals an increase in the expression of cadherins and associated functional partners in mid-secretory phase, compared to the early-secretory phase [11]. The localization of the three classical cadherin members, Ecadherin, N-cadherin and P-cadherin have been well characterized. The expression of these three cadherins are mainly restricted to the epithelial cell in the secretory phase, although their localisation specifically in the endometrial luminal epithelium is not reported [12, 13]. Further studies have revealed a potential dual function in facilitating embryo implantation [14, 15]. As adhesive molecules, the apical surface expression of cadherins can directly contribute to mechanical cell-cell adhesion. An in vitro functional study in a non-receptive endometrial epithelial cell line AN3-CA demonstrated that forced overexpression of E-cadherin in these cells significantly increased their receptivity to trophoblast-like spheroids formed by the BeWo choriocarcinoma cells [16]. By contrast, downregulation of E-cadherin in the lateral surface of the uterine epithelium in both human (in vitro) and mouse (in vivo) models may serve as a key mechanism to facilitate the loss of apical-basal polarity in the epithelial layer $[17,18]$. Such change is likely to avoid mutual repulsion between the embryo and the polarized endometrial luminal epithelial surface to facilitate embryo attachment and invasion [19].

Limited studies have investigated the localization and function of type II cadherin family members in the human endometrium. CDH11 is a predominant cadherin subtype in endometrial stromal cells in the secretory phase [20]. $\mathrm{CDH} 5$ is expressed in the late proliferative phase in endometrial explants [21] and in endometrial mesenchymal stromal cells [22]. An in vitro study demonstrated that expression of $\mathrm{CDH} 5$ in the mouse trophectoderm facilitates embryo implantation [23]. A previous characterization study revealed that $\mathrm{CDH} 6$ expression is decreased in the glandular epithelium and stromal cells in the receptive phase with no information available on the localization and expression in the luminal epithelium [24]. Another recent study confirmed that CDH6 immunolocalizes to the apical and lateral cell borders in the endometrial luminal epithelium in the mid-secretory phase [25]. Further assessment using a receptive endometrial epithelial cell line, Ishikawa cells, indicates that knockdown of $C D H 6$ in Ishikawa cells at high siRNA concentrations (50 and $100 \mathrm{nM}$ ) impact the integrity of Ishikawa cell monolayers compared to low siRNA concentrations (10 and $20 \mathrm{nM}$ ) or control siRNA [25].

To the best of our knowledge, there is no research exploring whether $\mathrm{CDH} 6$ plays a role in regulating endometrial epithelial cell adhesive capacity and receptivity and whether it is dysregulated in the endometrium of women with infertility during the receptive window. We examined the clinical relevance of $\mathrm{CDH} 6$ on receptivity by determining CDH6 immunostaining levels in midsecretory phase endometrium from fertile and infertile patients. We used the Ishikawa cells as an in vitro model of endometrial epithelial cells to determine whether siRNA knockdown of CDH6 compromised their 
adhesive capacity to HTR8/SVneo trophoblast spheroids. It has been previously identified that in neurons, other cadherins can compensate for the loss of CDH6 to maintain the correct positioning of neurons in the mouse model [26]. We thus also investigated the effect of $\mathrm{CDH} 6$ knockdown on the expression of other type II cadherin family members and $\mathrm{CDH} 6$ functional partners in Ishikawa cells.

\section{Methods}

\section{Antibodies and cell lines}

Rabbit polyclonal antibody against CDH6 (HPA007456) was purchased from Sigma (St. Louis, MO, USA). Horseradish Peroxidase (HRP) conjugated rabbit monoclonal antibody against Glyceraldehyde 3-phosphate dehydrogenase (GAPDH, \#3683) was from Cell Signaling Technology (Danvers, MA, USA). The Ishikawa cell line was provided by Dr. M. Nishida (Tsukuba University, Tochigi, Japan). The Ishikawa cell line is a wellestablished in vitro model of primary receptive endometrial epithelial cells derived from human endometrial adenocarcinoma cells that exhibits similar characteristics to endometrial luminal and glandular epithelial cells [27]. Besides the expression of hormone receptors being similar to normal primary endometrial cells [28], Ishikawa cells also possess apical adhesiveness and are appropriate to study endometrial receptivity and embryo attachment [27]. The HTR8/SVneo trophoblast cell line (CRL-3271) was purchased from the ATCC and cultured as in the manufacturer's instructions.

\section{Endometrial tissue collection}

Written informed consent was obtained from each patient before surgery, with protocols approved by the $\mathrm{Hu}$ man Research Ethics Committee at Monash Health (ID: \#03066B) and the Royal Women's Hospital (SSA1813). All women (26-42 years of age) consented had regular menstrual cycles (28-32 day), were not using intrauterine contraceptives and had not used hormones for at least 3 months before surgery. Fertile women had proven parity ( $\geq 1$ parous pregnancy) and were having surgery for mirena insertion, benign ovarian cyst assessment or polypectomy. Infertile women had primary unexplained infertility defined as being unable to conceive after oneyear and had no apparent endometrial dysfunction diagnosed using routine fertility investigations (hysteroscopic and laparoscopic diagnosis, including endometriosis, endometritis or other endometrial related disorders). Partners of the infertile group had normal sperm analysis including sperm counts, motility and morphology. The endometrial tissue samples were collected by curettage and were from the functionalis layer. The collected endometrium were examined by gynecological pathologists based at the Royal Women's Hospital to confirm the cycle stage and absence of endometrial dysfunction.

\section{CDH6 siRNA transfection}

We transfected the Ishikawa cells with three different concentrations of CDH6 siRNA based on a previous study [25]. Ishikawa cells at $70-80 \%$ confluency were transfected with Lipofectamine RNAiMAX and OptiMEM medium (Thermo, Waltham, MA, USA) containing CDH6 siRNA $(10,20$ or $50 \mathrm{nM})$ or scrambled control $(50 \mathrm{nM})$ (Dharmacon, Lafayette, CO, USA) according to the manufacturer's instructions. Before transfection, cells were washed three times with phosphate-buffered saline (PBS) to remove antibiotics. After $24 \mathrm{~h}$ the transfection medium was replaced with fresh culture medium and Ishikawa cells were cultured for $48 \mathrm{~h}$ before being subjected to spheroid adhesion assay or other downstream analyses.

\section{Immunohistochemistry and immunocytochemistry}

Human fertile and infertile endometrial tissues (midsecretory phase defined as days 20-24 of an idealized 28 -day menstrual cycle) [29] were fixed in $10 \%$ formalin, embedded in paraffin and sectioned at $4 \mu \mathrm{m}$ thickness. Slides were dewaxed, rehydrated and subjected to antigen retrieval under optimized condition (microwaving in $10 \mathrm{mM}$ sodium citrate for $5 \mathrm{~min}$ ). Endogenous peroxidase was blocked using $3 \%$ hydrogen peroxide in methanol for $15 \mathrm{~min}$. Slides were then incubated with nonimmune blocking containing $10 \%$ goat serum and $2 \%$ human serum in Tris-buffered saline (TBS) for $45 \mathrm{~min}$ at room temperature (RT). CDH6 antibody was added at the concentration of $0.25 \mu \mathrm{g} / \mathrm{mL}$ overnight at $4{ }^{\circ} \mathrm{C}$. Equivalent isotype control (Dako, X0903) was included in which sections were incubated with a normal rabbit immunoglobulin fraction at the same concertation $(0.25 \mu \mathrm{g} / \mathrm{mL})$. Slides were washed with TBS-Tween $0.6 \%$ $(\mathrm{v} / \mathrm{v})$ and positive signaling was revealed via the avidinbiotin- diaminobenzidine system. Sections were counterstained with haematoxylin to indicate cell nuclei (blue). Slides were then mounted with DPX and imaged using an Olympus light microscope. Staining intensity scores were determined by two individual scorers blinded to the patient characteristic, as previously described [30]. Briefly, a score of 0 denoted no CDH6 staining and 3 was maximal staining. Each score was based on overall staining intensity of the whole endometrial section. Scores were analyzed and plotted using Graphpad Prism 7. For immunocytochemistry staining of cell cultures, the cells were settled onto Ibidi $\mu$-slide culture chambers. Cells were then fixed in $4 \%$ paraformaldehyde for $15 \mathrm{~min}$ and permeabilized by incubation in $0.1 \%$ Triton 
X-100 for $10 \mathrm{~min}$. After PBS wash, cells were immunolabeled as described for endometrial sections.

\section{Spheroid adhesion assay}

HTR8/SVneo cells were plated in a U shape and ultralow attachment 96 well plate (Corning, NY, USA) and cultured for $48 \mathrm{~h}$ to form spheroids $(2000$ cells/spheroid). Spheroids were then harvested and transferred to transfected Ishikawa cell monolayer (20 spheroids/well of 96 well plate) to initiate spheroid adhesion assay. Briefly, original spheroid number in each well was determined using a light microscope before been subjected to $4 \mathrm{~h}$ co-culture with Ishikawa monolayer. Following incubation, each well was gently washed once by adding $150 \mu \mathrm{L}$ PBS to remove non-adherent spheroids. The remaining spheroids (adhered spheroids) were counted and attachment was expressed as a percentage of the original spheroid number as previously reported [31].

\section{RNA isolation and RT-q-PCR}

Ishikawa cells were lysed with TRI Reagent (Sigma). RNA was isolated according to the manufacturer's protocol and treated with RNase-free DNase set (Qiagen, Germantown, MD, USA) to remove genomic DNA contamination. RNA concentration was determined by Nanodrop spectrophotometers (Thermo). For reverse transcription, $300 \mathrm{ng}$ total RNA was converted to cDNA using SuperScript ${ }^{\text {TM }}$ III First-Strand Synthesis System (18080-051, Thermo). qPCR was performed on the Applied Biosystems ViiA7 system using SYBR Green Master Mix $\left(4,367,659\right.$, Thermo) as follows: $95^{\circ} \mathrm{C}$ for $10 \mathrm{~min}$ and 40 cycles of $95^{\circ} \mathrm{C}$ for $15 \mathrm{~s}$ followed by $60{ }^{\circ} \mathrm{C}$ for 1 min. Primers used were summarized in Additional file 2. Gene expression was normalized to $18 S$. Relative expression levels were calculated using the comparative cycle threshold method $(\Delta \Delta \mathrm{Ct})$.

\section{SDS-PAGE and immunoblotting}

The organic phase from TRI Reagent based RNA isolation was collected for protein extraction with the detailed protocol optimized by a previous study [32]. Proteins were then resolved by SDS-PAGE $(150 \mathrm{~V}, 1 \mathrm{~h})$ and transferred to PVDF membranes (100 V, $1 \mathrm{~h})$. Membranes were then blocked with $5 \%$ skim milk and incubated with the CDH6 antibody (1:1000) overnight at $4{ }^{\circ} \mathrm{C}$. Membranes were washed with TBS-Tween $0.1 \%$ (v/ v) and incubated with HRP conjugated secondary antibody against rabbit and HRP-GAPDH (1:3000, as a loading control). After three additional washes, labeled proteins (CDH6 and GAPDH) were detected by chemiluminescence (Thermo).

\section{Statistics}

Statistical analysis was performed using PRISM 8.0 and two-tailed unpaired student's t-test or one-way ANOVA as appropriate with a significance threshold of $P<0.05$. Data were presented as the mean \pm SEM.

\section{Results \\ CDH6 expression is reduced in the mid-secretory phase endometrium from women with infertility, compared to fertile group}

To investigate the functional significance of CDH6 in the human endometrium, we first sought to determine the clinical relevance of this target in infertility by assessing its immunolocalization in mid-secretory phase endometrium from women with normal fertility (fertile) and primary infertility (infertile). In our immunostaining analysis of fertile endometrium, in addition to membrane staining, CDH6 was also localized to the cytoplasm of the fertile endometrium (Fig. 1a). By contrast, the infertile endometrium showed a reduced level of CDH6 staining in the luminal and glandular epithelium compared to the fertile group. Semi-quantification of the CDH6 staining intensity confirmed the reduction to be significant $(P<0.05)$ in both luminal and glandular epithelium. No significant difference was found in the stromal cells between fertile and infertile groups (Fig. 1b). The specificity of CDH6 labeling was confirmed by the inclusion of an isotype control and as expected, no staining was revealed (Fig. 1a).

Knockdown of $\mathrm{CDH6}$ in the Ishikawa cells impaired HTR8/ SVneo spheroid adhesion

We next used Ishikawa cells in combination with HTR8/ SVneo spheroids to determine the functional consequences of $\mathrm{CDH} 6$ knockdown on endometrial epithelial adhesive capacity. Prior to use, these cells were assessed for their expression of CDH6 by immunocytochemistry. Consistent with the localization of $\mathrm{CDH} 6$ in the fertile endometrium (Fig. 1a), CDH6 localized to the membrane of Ishikawa cells with moderate staining appearing in the cytoplasm (Fig. 2 a). Based on the similar expression patterns compared to luminal epithelium in the fertile endometrium, the Ishikawa cells were deemed a suitable model to explore CDH6 function. We also demonstrated for the first time that in HTR8/SVneo cells, CDH6 localized to the cell cytoplasm and membrane (Fig. 2b).

We transfected the Ishikawa cells with three different concentrations of CDH6 siRNA. Our qPCR data confirmed that $C D H 6$ siRNA treatment at all concentrations significantly reduced $\mathrm{CDH} 6$ expression compared to scrambled control (Fig. 3a, $P<0.001$ ). The extent of CDH6 reduction was siRNA concentration dependent, with the lowest expression of $\mathrm{CDH} 6$ being recorded in the Ishikawa cells that had the highest concentration of 


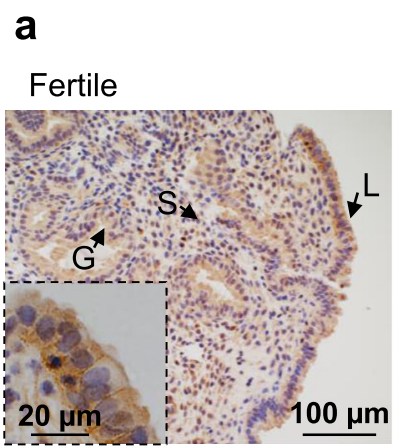

Infertile

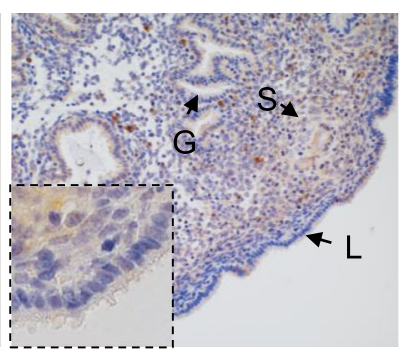

Isotype control

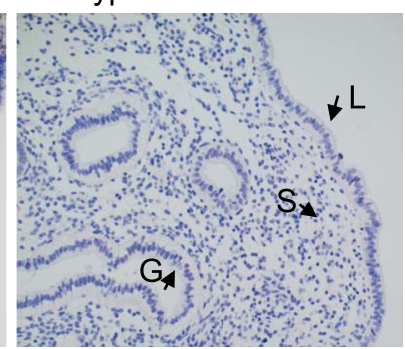

b

L

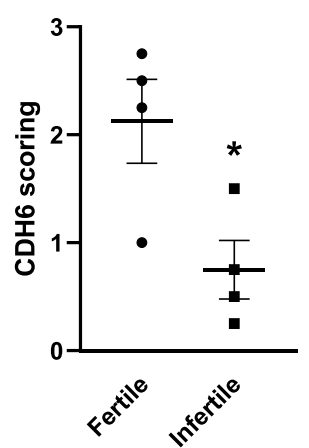

G

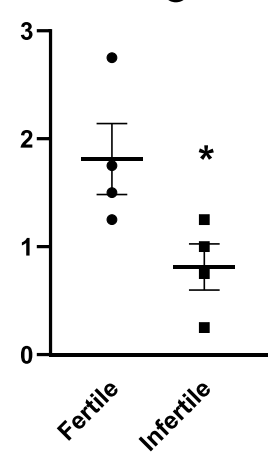

S

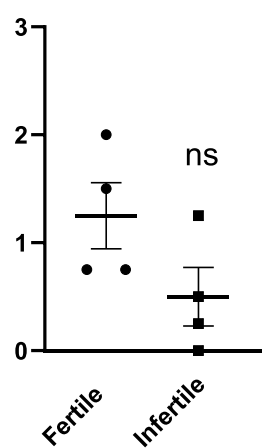

Fig. 1 Comparison of $\mathrm{CDH} 6$ immunolocalization in fertile and infertile mid-secretory phase endometrium. a CDH6 immunolocalized to the luminal epithelium (L), glandular epithelium $(G)$ and stromal cells $(S)$. Higher magnification images are outlined. The specificity of CDH6 labeling was confirmed through the inclusion of an isotype control in which the non-immune antibody of the same isotype was substituted for the CDH6 antibody at the same concertation. Sections were counterstained with hematoxylin to indicate the cell nuclei (blue). b Staining intensity of CDH6 was semi-quantitated by scoring staining in tissues blinded to fertility status. Data were presented as mean \pm SEM. $(n=4)$. * $P<0.05$, ns: no significant difference

CDH6 siRNA treatment (Fig. 3a). Immunoblotting was also used to assess the CDH6 protein levels after $\mathrm{CDH} 6$ siRNA treatments and similar to the effect on $C D H 6$ mRNA, we confirmed the knockdown of CDH6 protein after siRNA treatment at the different concentrations (Fig. 3b). Following knockdown of CDH6 in the Ishikawa cells, HTR8/SVneo spheroids were added and their adhesive capability on the Ishikawa monolayer was determined. As shown in Fig. 3c, Ishikawa cells transfected with $\mathrm{CDH6}$ siRNA at $50 \mathrm{nM}$ had significantly reduced spheroid adhesion compared to scrambled control $(P<0.05)$. No significant difference in spheroid adhesion was observed with CDH6 siRNA treatment at 10 and $20 \mathrm{nM}$ compared to scrambled control. Notably, no discernible effect on Ishikawa cell monolayer integrity / morphology was recorded with CDH6 siRNA treatment at $50 \mathrm{nM}$ which is in contrast to a previous report (Additional file 1).

The effect of $C D H 6$ knockdown on the expression of $C D H$ family members and functional partners

Since previous studies have shown that cadherin family members share moderate levels of functional redundancy [33, 34], it is possible that other type II cadherin members may compensate for the loss of CDH6 in the Ishikawa cells as no significant effect on HTR8/ SVneo spheroid adhesion was recorded at 10 and $20 \mathrm{nM}$ CDH6 siRNA treatments compared to scrambled control (Fig. 3c). The expression of type II cadherin members in Ishikawa cells following $\mathrm{CDH} 6$ knockdown was explored by qPCR. This analysis indicated that in scrambled control treated Ishikawa cells, $\mathrm{CDH} 12$ and $\mathrm{CDH} 24$ were expressed at relatively high levels (average raw $\mathrm{Ct}$ value 26) compared to $\mathrm{CDH} 5$ and $\mathrm{CDH} 13$ (average raw $\mathrm{Ct}$ value 32-33) (Additional file 3). CDH11 expression was undetectable in Ishikawa cells (data not shown). Among all the type II cadherin family members examined, CDH6 knockdown in Ishikawa cells had no significant effect on the expression levels of $\mathrm{CDH}, \mathrm{CDH} 12$ and CDH13 compared to scrambled control while $C D H 24$ expression was only significantly increased with $\mathrm{CDH}$ siRNA treatment at $10 \mathrm{nM}$ (Fig. 4a, $P<0.05$ ). CDH6 reduction in the Ishikawa cells did not affect the expression levels of the CDH6 functional partners, Catenin family members including Catenin alpha 1 (CTNNA1), 


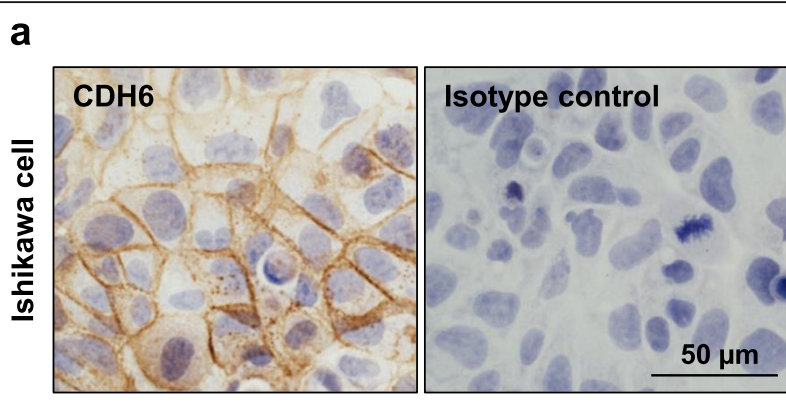

b

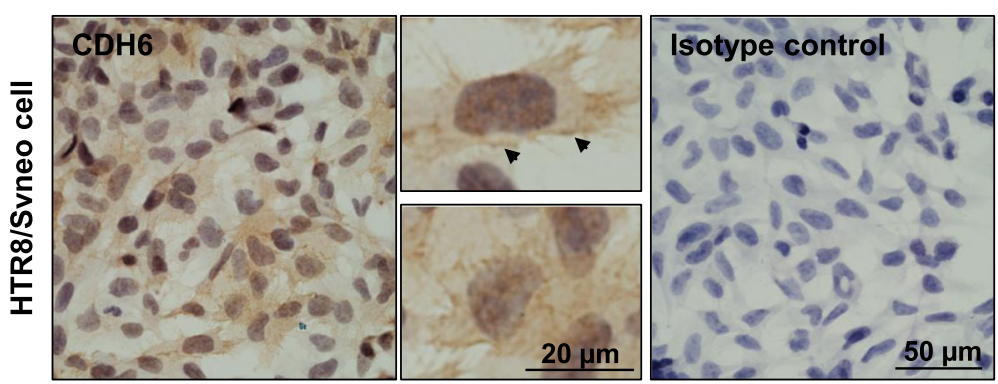

Fig. 2 Immunocytochemistry detection of CDH6 in the Ishikawa cells and HTR8/SVneo cells. a In Ishikawa cells, CDH6 localization was detected to the plasma membrane with moderate staining appearing in the cytoplasm. b A similar localization was observed in the HTR8/SVneo cells (arrows) with extra staining also found in the cytoplasm. Higher magnification images of CDH6 localization in HTR8/SVneo cells are depicted on the right of panels. The specificity of $\mathrm{CDH} 6$ labeling was confirmed through the inclusion of an isotype control as described in Fig. 1. Sections were counterstained with hematoxylin to indicate the cell nuclei (blue)

Catenin beta 1 (CTNNB1) and Catenin delta 1 endometrium during the receptive window. We used (CTNND1) (Fig. 4b).

\section{Discussion}

Adhesive proteins in the endometrial luminal epithelium fulfill essential roles in facilitating embryo attachment. In this study, we demonstrated for the first time that CDH6 reduction was associated with infertile
Ishikawa cells as an in vitro model to explore the functional consequences of $C D H 6$ knockdown on their adhesive capacity to HTR8/SVneo spheroids. We demonstrated that knockdown of $\mathrm{CDH} 6$ significantly reduced the spheroid adhesion compared to scrambled control under $50 \mathrm{nM}$ condition and did not affect the expression of other type II cadherin family members or
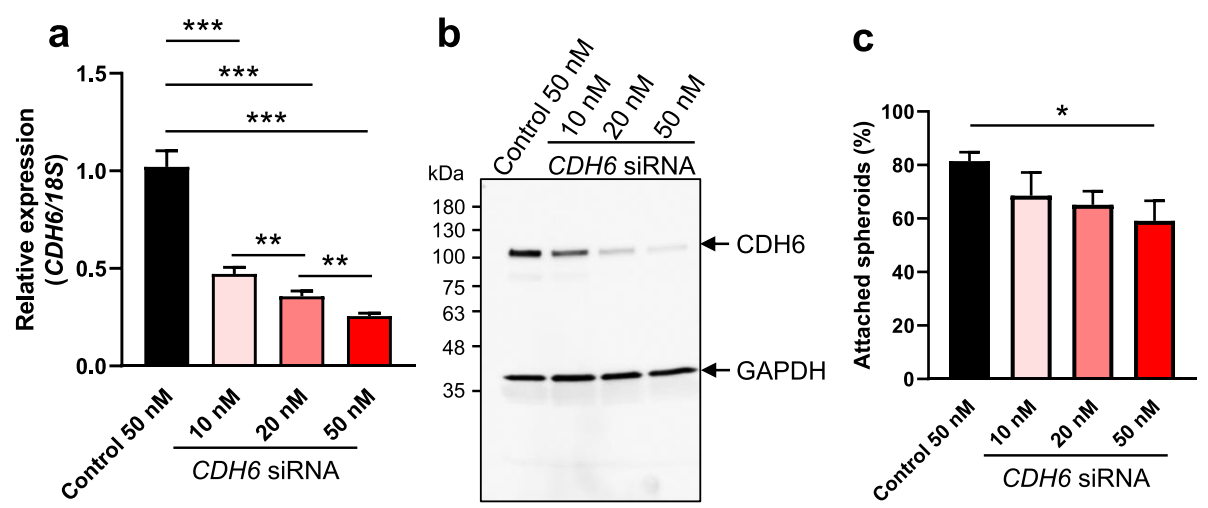

Fig. 3 Examination of the effect of $\mathrm{CDH} 6$ knockdown on Ishikawa cell adhesive capacity. Ishikawa cells were transfected with either scrambled control $(50 \mathrm{nM})$ or CDH6 siRNA (10, 20 or $50 \mathrm{nM}$ ) before HTR8/SVneo spheroid adhesion assay. a CDH6 knockdown was determined by qPCR. Expression levels were normalized to $18 \mathrm{~S}(n=7)$. $\mathbf{b}$ Immunoblotting was also used to determine the CDH6 expression. Blots were co-probed with an anti-GAPDH antibody to confirm equivalent protein loading of each sample. c A siRNA concentration-dependent reduction of the adhesion was observed in Ishikawa cells with the highest concentration of $\mathrm{CDH} 6$ siRNA (50 nM) significantly compromised the spheroid adhesion compared to scrambled control. Data were presented as mean \pm SEM. ${ }^{*} P<0.05,{ }^{*} P<0.01,{ }^{* * *} P<0.001$ 


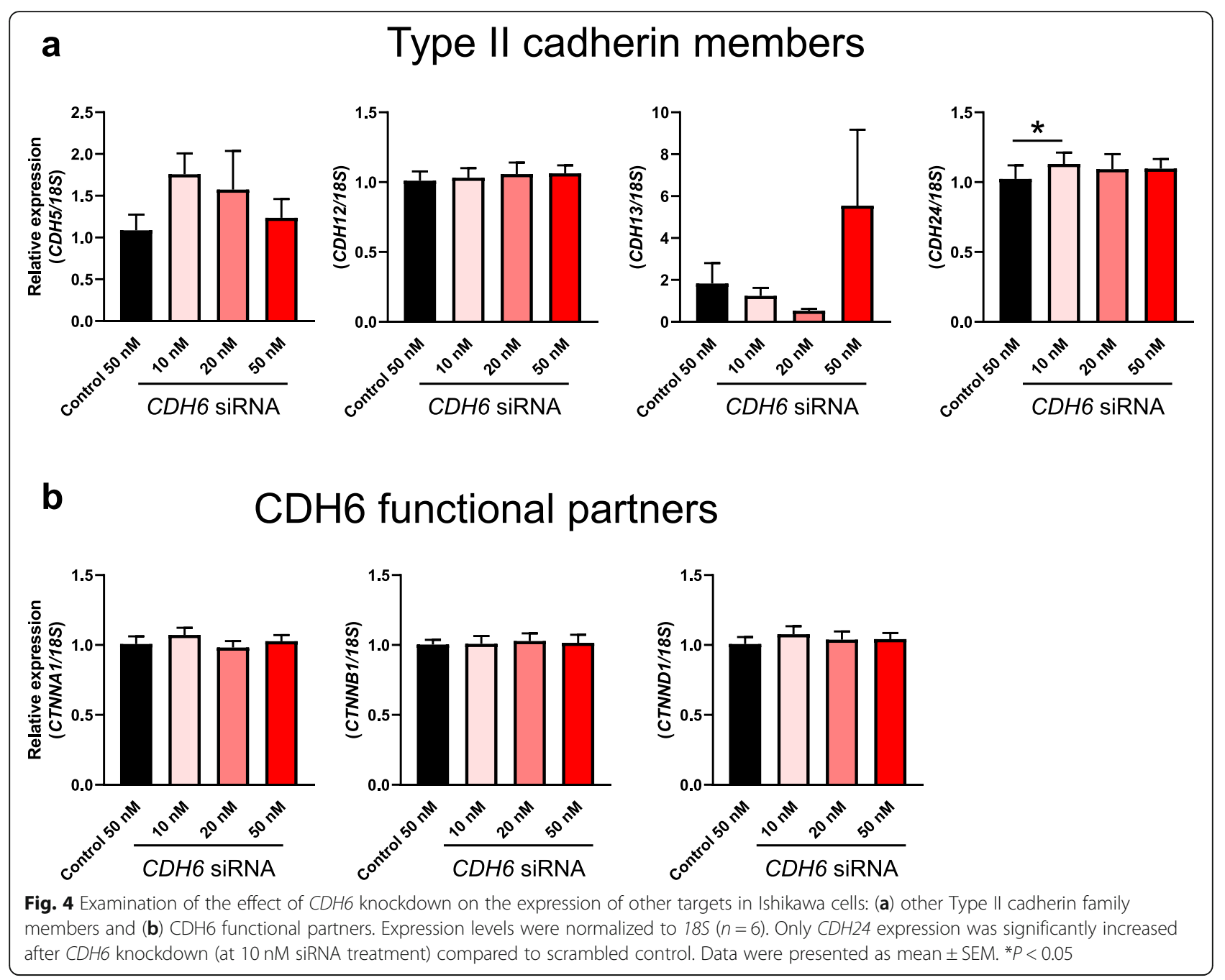

CDH6 functional partners, indicating CDH6 has a nonredundant role in regulating endometrial receptivity.

CDH6 belongs to type II classical cadherin and it regulates cell adhesion via a homophilic binding to its own family members. In order to regulate embryo adhesion, cadherin family members are required to be expressed in both endometrial epithelial cells and blastocyst trophectoderm. qPCR analysis from our study revealed that all type II cadherin family members were expressed in the Ishikawa cells. Gene expression analysis of trophectoderm isolated from preimplantation human embryos demonstrates all type II cadherin family members are expressed in the trophectoderm [35]. This indicates that all type II classical cadherins are able to directly regulate embryo adhesion onto the endometrial luminal epithelium. Our data showed that although lower concentrations of $\mathrm{CDH} 6$ siRNA treatment (10 and $20 \mathrm{nM})$ in the Ishikawa cells did not compromise spheroid adhesion, $50 \mathrm{nM}$ CDH6 siRNA treatment significantly reduced their adhesive capacity to HTR8/SVneo spheroids suggesting that either the level of CDH6 was critical for adhesion or the existence of other type II classical cadherins were not able to compensate for the severe loss of CDH6. It is not unusual that cadherin family members play non-redundant roles in cell adhesion and invasion. A previous study in mouse embryos reveals a unique role of E-cadherin in regulating the formation of polarized functional trophectoderm by demonstrating that the replacement of E-cadherin by $\mathrm{N}$-cadherin is not sufficient to form an intact trophectoderm [36]. After embryo attachment, the trophectoderm differentiates into trophoblast and starts to invade into the uterus. It has been revealed that in the invasive front of extravillous cytotrophoblasts, $\mathrm{CDH} 6$ is the predominant cadherin subtype and its expression promotes the cell invasive capacity [20,37].

This leads to an intriguing notion of cadherin expression that has been recorded during epithelial to mesenchymal transition in embryonic development, namely the cadherin switch [38]. During this process, the 
expression of the epithelial cell marker E-cadherin is reduced whereas the expression of another cadherin family member $\mathrm{N}$-cadherin is increased. Such an expression switch coincides with a morphological and phenotypic transition of the pre-migrating cells [39]. A similar change in cadherin expression has also been recorded in tumor cells. Loss of E-cadherin and increased expression of N-cadherin and CDH11 in the human prostate cancer cells is able to change the invasive capacity and metastasis of the cells [40]. In the mid-secretory phase human endometrium, in contrast to the localization of CDH6 in the apical and lateral surface of endometrial luminal epithelium, E-cadherin protein expression is reduced and shows minimal levels [41]. Such an expression reduction has been proven essential for embryo implantation and invasion in mice [17]. It is likely that selective changes in expression of E-cadherin and $\mathrm{CDH} 6$, along with other notable cadherin family members that have been reported in the human endometrium [12, 13, 20] contribute to a functional transition that is required for successful embryo implantation.

A particular curiosity of this hypothesis is how the differential expression of the same cadherin family members lead to a functional transition in endometrial epithelial cells. One possible explanation is that different family members may have different isoforms. The isoform differences enable even the same cadherin family member to have different functional capacities. It has recently been demonstrated that CDH6 has two isoforms that are inherently different: $\mathrm{CDH} 6$-long isoform and CDH6-short isoform [37]. The difference between these two isoforms is that the CDH6-short isoform does not have an intracellular domain to interact with its functional partners [37] and it may lose the ability to activate downstream signaling pathways. It is likely that this isoform only functions as an adhesive molecule during cell-cell interactions. The antibody we used in this study binds to the extracellular domain thus recognizes both isoforms. We remain uncertain if these two isoforms co-exist in the endometrial luminal epithelium to regulate different functional aspects of the implantation process. Different isoforms of cadherin family members may fulfill specific functional requirements within a specific cell type or development stage.

Previous studies have also proposed a cellular 'redistribution' theory that may contribute to the functional complexity of the cadherins. In the human endometrium, the lateral surface expression of $\mathrm{CDH} 6$ is essential to form the adherens junctions to maintain the integrity of the endometrial luminal epithelium before implantation. Once the embryo contacts the endometrial luminal epithelium, the lateral adherens junction proteins such as $\mathrm{CDH} 6$ may redistribute to the apical surface to facilitate the attachment of the embryo and such redistribution may break down the adherens junctions to allow or facilitate embryo invasion [25, 42]. The redistribution of $\mathrm{CDH} 6$ also releases the cadherin functional partners such as catenin proteins that are required to form adherens junctions. Another role of catenin proteins is to participate in $\mathrm{Wnt} / \beta$-catenin (CTNNB1) signaling that is essential for implantation in vivo in mice [43]. Wnt/ $\beta$-catenin (CTNNB1) signaling activation similarly requires the local stimulus of the embryo [43] which supports the 'redistribution' theory. Our immunohistochemistry data revealed that $\mathrm{CDH} 6$ was downregulated in the apical and lateral surfaces of the endometrial luminal epithelium in the infertile endometrium during the mid-secretory phase suggesting $\mathrm{CDH} 6$ affects both adhesion and integrity of the endometrial luminal epithelium.

Several mechanisms can reduce CDH6 expression in the infertile endometrium. microRNA downregulates gene expression [44] and our previous studies reveal that specific microRNAs are increased in the infertile human endometrium and affect endometrial adhesive capacity and receptivity by downregulating essential gene targets [30, 31]. CDH6 is a direct gene target of miR-223-3p and forced overexpression of miR-223-3p in cultured osteosarcoma cells reduces $\mathrm{CDH} 6$ expression and inhibits cell invasion and migration [45]. miR-223-3p also suppresses the expression of leukemia inhibitory factor (LIF) during the implantation window in mouse uterus [46], a target that is essential for embryo implantation in both humans and mice $[47,48]$. A previous study confirms the upregulation of miR-223-3p in human endometrium with a compromised receptivity phenotype and its interaction with LIF [49]. In support, in our recent study we reveal that miR-223-3p is detected at low levels in the primary fertile human endometrial epithelial cells [50]. However, whether $C D H 6$ is directly regulated by miR-223-3p in the infertile human endometrium is unknown. Similarly, CDH6 may be downregulated in infertile endometrium epigenetically by DNA methylation. An in vitro study on human endometrial epithelial cell line AN3-CA has confirmed that E-cadherin gene expression is negatively controlled by DNA methyltransferase enzymes. Inhibition of these enzymes increases the expression of Ecadherin and switch the non-receptive endometrial epithelial cells to become receptive to trophoblast-like spheroids formed by the BeWo choriocarcinoma cells [16]. In support, an in vivo mouse model has revealed that increased DNA methylation on the promoter of homeobox A10 (Hoxa10) reduces the expression of Hoxa10 and directly affects endometrial receptivity [51]. There are no studies that have investigated whether the downregulation of $\mathrm{CDH} 6$ is related to increased DNA methylation in any biological system. Whether this is the case in the infertile endometrium warrants further investigation. 
Ishikawa cells transfected with $50 \mathrm{nM}$ of $\mathrm{CDH} 6$ siRNA did not compromise cell integrity which is in contrast to a previous report [25]. This may have been due to methodological differences between the two studies. One notable difference in our study is that we transfected the Ishikawa cells at $70-80 \%$ confluency while in the previous report the cells were transfected at $40-50 \%$ confluency. After transfection we cultured the Ishikawa cells for $48 \mathrm{~h}$ while in the previous study, the Ishikawa cells were cultured for up to $120 \mathrm{~h}$ which may have severely impacted the cell integrity.

\section{Conclusions}

In conclusion, our study has provided evidence that CDH6 was abnormally reduced in infertile endometrium during the receptive window. Functional analysis demonstrated that CDH6 may play a non-redundant role in the regulation of endometrial receptivity. Further studies are encouraged to use primary endometrial epithelial cells to confirm these results. Overall our study suggests that CDH6 may be useful as a biomarker or treatment target for dysregulated receptivity in women with infertility.

\section{Supplementary information}

Supplementary information accompanies this paper at https://doi.org/10. 1186/s12958-020-00624-W.

Additional file 1. $\mathrm{CDH} 6$ siRNA treatment at $50 \mathrm{nM}$ has no discernable effect on Ishikawa cell integrity. After adhesion assay, attached spheroids on the Ishikawa cell monolayer were indicated with arrows. A higher magnification image of the Ishikawa cells was depicted on the right panel with its original location indicated by outlines on the left.

Additional file 2. Primers used throughout this study.

Additional file 3. Detection of Type II cadherin family members and $\mathrm{CDH} 6$ functional partners in the Ishikawa cells. Expression levels were assessed by raw $\mathrm{Ct}$ value $(n=6)$.

\section{Abbreviations}

CDH6: Cadherin 6; HRP: Horseradish peroxidase; GAPDH: Glyceraldehyde 3phosphate dehydrogenase; TBS: Tris-buffered saline; PBS: Phosphate-buffered saline; RT: Room temperature; LIF: Leukemia inhibitory factor;

Hoxa10: Homeobox A10

\section{Acknowledgements}

The authors are grateful to Ms. Emily-jane Bromley for orchestrating the tissue collection and the women who donated the endometrial tissue used in this study.

\section{Authors' contributions}

W.Z. conducted the experiments and generated the manuscript. L.S. conducted immunohistochemistry experiments and reviewed the manuscript. E.D. conceived and designed the study, contributed to data interpretation and analysis, and manuscript preparation and review. All authors approved the final version and submission of this article.

\section{Funding}

This work was supported by a project grant and a senior research fellowship from the National Health and Medical Research Council (NHMRC) of Australia to E.D. W.Z. was supported by an Early Career Researcher Grant (University of Melbourne). The authors have no competing interests to declare.

\section{Availability of data and materials}

All data generated through this study are included in this article.

\section{Ethics approval and consent to participate}

Written informed consent was obtained from each patient and the study was approved by the Human Research Ethics Committee at the Royal Women's Hospital (ID: \#03066B).

\section{Consent for publication}

Not applicable.

\section{Competing interests}

The authors report no competing interests.

Received: 20 April 2020 Accepted: 23 June 2020

Published online: 29 June 2020

\section{References}

1. Boivin J, Bunting L, Collins JA, Nygren KG. International estimates of infertility prevalence and treatment-seeking: potential need and demand for infertility medical care. Hum Reprod. 2007;22:1506-12.

2. Norwitz ER, Schust DJ, Fisher SJ. Implantation and the survival of early pregnancy. N Engl J Med. 2001;345:1400-8.

3. Dimitriadis $E$, Nie G, Hannan NJ, Paiva P, Salamonsen LA. Local regulation of implantation at the human fetal-maternal interface. Int J Dev Biol. 2009;54: 313-22.

4. Dimitriadis E, White C, Jones R, Salamonsen L. Cytokines, chemokines and growth factors in endometrium related to implantation. Hum Reprod Update. 2005;11:613-30.

5. Koot Y, Teklenburg G, Salker M, Brosens J, Macklon N. Molecular aspects of implantation failure. Biochim Biophys Acta. 1822;2012:1943-50.

6. Evans J, Salamonsen LA, Winship A, Menkhorst E, Nie G, Gargett CE, Dimitriadis E. Fertile ground: human endometrial programming and lessons in health and disease. Nat Rev Endocrinol. 2016;12:654-67.

7. Bergh PA, Navot D. The impact of embryonic development and endometrial maturity on the timing of implantation. Fertil Steril. 1992;58: 537-42.

8. Lessey BA. Assessment of endometrial receptivity. Fertil Steril. 2011;96:522-9.

9. Helfrich MH, Stenbeck G, Nesbitt SA, Horton MA. Integrins and other cell surface attachment molecules of bone cells. In: Bilezikian J, Raisz L, Marton TJ, editors. Principles of Bone Biology. 3rd ed. Academic Press; 2008. p. 385-424.

10. Halbleib JM, Nelson WJ. Cadherins in development: cell adhesion, sorting, and tissue morphogenesis. Genes Dev. 2006;20:3199-214.

11. Carson DD, Lagow E, Thathiah A, Al-Shami R, Farach-Carson MC, Vernon M, Yuan L, Fritz MA, Lessey B. Changes in gene expression during the early to mid-luteal (receptive phase) transition in human endometrium detected by high-density microarray screening. Mol Hum Reprod. 2002;8:871-9.

12. Poncelet C, Leblanc M, Walker-Combrouze F, Soriano D, Feldmann G, Madelenat P, Scoazec JY, Daraï E. Expression of cadherins and CD44 isoforms in human endometrium and peritoneal endometriosis. Acta Obstet Gynecol Scand. 2002;81:195-203.

13. van der Linden PJ, de Goeij AF, Dunselman GA, Erkens HW, Evers JL. Expression of cadherins and integrins in human endometrium throughout the menstrual cycle. Fertil Steril. 1995;63:1210-6.

14. Singh $H$, Aplin JD. Adhesion molecules in endometrial epithelium: tissue integrity and embryo implantation. J Anat. 2009;215:3-13

15. Coutifaris C, Kao L, Sehdev H, Chin U, Babalola G, Blaschuk O, Strauss J. Ecadherin expression during the differentiation of human trophoblasts. Development. 1991:113:767-77.

16. Rahnama F, Thompson B, Steiner M, Shafiei F, Lobie PE, Mitchell MD. Epigenetic regulation of $\mathrm{E}$-cadherin controls endometrial receptivity. Endocrinology. 2009;150:1466-72.

17. Fullerton PT, Monsivais D, Kommagani R, Matzuk MM. Follistatin is critical for mouse uterine receptivity and decidualization. Proc Natl Acad Sci U S A 2017;114:E4772-81.

18. Thie M, Harrach-Ruprechtb B, Sauere H, Fuchsa P, Albersa A, Denkera H-W Cell adhesion to the apical pole of epithelium: a function of ce11 polarity. Eur J Cell Biol. 1995;66:180-91.

19. Whitby S, Salamonsen LA, Evans J. The endometrial polarity paradox: differential regulation of polarity within secretory-phase human endometrium. Endocrinology. 2018;159:506-18. 
20. Maccalman CD, Getsios S, Chen GT. Type 2 cadherins in the human endometrium and placenta: their putative roles in human implantation and placentation. Am J Reprod Immunol. 1998;39:96-107.

21. Dassen H, Punyadeera C, Kamps R, Klomp J, Dunselman G, Dijcks F, De Goeij A, Ederveen A, Groothuis P. Progesterone regulation of implantationrelated genes: new insights into the role of oestrogen. Cell Mol Life Sci. 2007;64:1009.

22. Gargett CE, Schwab KE, Deane JA. Endometrial stem/progenitor cells: the first 10 years. Hum Reprod Update. 2016;22:137-63.

23. Vilella F, Moreno-Moya JM, Balaguer N, Grasso A, Herrero M, Martínez S, Marcilla A, Simón C. Hsa-miR-30d, secreted by the human endometrium, is taken up by the pre-implantation embryo and might modify its transcriptome. Development. 2015;142:3210-21.

24. Getsios S, Chen GT, Stephenson MD, Leclerc P, Blaschuk OW, MacCalman CD. Regulated expression of cadherin- 6 and cadherin-11 in the glandular epithelial and stromal cells of the human endometrium. Dev Dyn. 1998;211: 238-47.

25. Singh $\mathrm{H}$, Aplin J. Endometrial apical glycoproteomic analysis reveals roles for cadherin 6, desmoglein-2 and plexin b2 in epithelial integrity. Mol Hum Reprod. 2015;21:81-94.

26. Osterhout JA, Josten N, Yamada J, Pan F, Wu S-W, Nguyen PL, Panagiotakos G, Inoue YU, Egusa SF, Volgyi B. Cadherin-6 mediates axon-target matching in a non-image-forming visual circuit. Neuron. 2011;71:632-9.

27. Hannan NJ, Paiva P, Dimitriadis E, Salamonsen LA. Models for study of human embryo implantation: choice of cell lines? Biol Reprod. 2010;82:235-45.

28. Nishida M. The Ishikawa cells from birth to the present. Hum Cell. 2002;15: 104-17.

29. Achache $H$, Revel A. Endometrial receptivity markers, the journey to successful embryo implantation. Hum Reprod Update. 2006:12:731-46.

30. Griffiths M, Van Sinderen M, Rainczuk K, Dimitriadis E. miR-29c overexpression and COL4A1 downregulation in infertile human endometrium reduces endometrial epithelial cell adhesive capacity in vitro implying roles in receptivity. Sci Rep. 2019;9:8644.

31. Winship A, Ton A, Van Sinderen M, Menkhorst E, Rainczuk K, Griffiths M, Cuman C, Dimitriadis E. Mouse double minute homologue 2 (MDM2) downregulation by miR-661 impairs human endometrial epithelial cel adhesive capacity. Reprod Fertil Dev. 2018;30:477-86.

32. Kopec AM, Rivera PD, Lacagnina MJ, Hanamsagar R, Bilbo SD. Optimized solubilization of TRIzol-precipitated protein permits Western blotting analysis to maximize data available from brain tissue. J Neurosci Methods. 2017;280:64-76

33. Matsunaga E, Okanoya K. Cadherins: potential regulators in the faculty of language. Curr Opin Neurobiol. 2014;28:28-33.

34. Jensen PJ, Telegan B, Lavker RM, Wheelock MJ. E-cadherin and P-cadherin have partially redundant roles in human epidermal stratification. Cell Tissue Res. 1997;288:307-16.

35. Adjaye J, Huntriss J, Herwig R, BenKahla A, Brink TC, Wierling C, Hultschig C, Groth D, Yaspo ML, Picton HM. Primary differentiation in the human blastocyst: comparative molecular portraits of inner cell mass and trophectoderm cells. Stem Cells. 2005;23:1514-25.

36. Kan NG, Stemmler MP, Junghans D, Kanzler B, de Vries WN, Dominis M, Kemler R. Gene replacement reveals a specific role for E-cadherin in the formation of a functional trophectoderm. Development. 2007;134:31-41.

37. Sancisi V, Gandolfi G, Ragazzi M, Nicoli D, Tamagnini I, Piana S, Ciarrocchi A. Cadherin 6 is a new RUNX2 target in TGF- $\beta$ signalling pathway. PLoS One. 2013;8.

38. Gheldof A, Berx G. Cadherins and epithelial-to-mesenchymal transition. Prog Mol Biol Transl Sci. 2013;116:317-36.

39. Savagner P. Epithelial-mesenchymal transitions: from cell plasticity to concept elasticity. Curr Top Dev Biol. 2015;112:273-300.

40. Tomita K, Van Bokhoven A, van Leenders GJ, Ruijter ET, Jansen CF, Bussemakers MJ, Schalken JA. Cadherin switching in human prostate cancer progression. Cancer Res. 2000;60:3650-4.

41. Matsuzaki S, Darcha C, Maleysson E, Canis M, Mage G. Impaired downregulation of $\mathrm{E}$-cadherin and $\beta$-catenin protein expression in endometrial epithelial cells in the mid-secretory endometrium of infertile patients with endometriosis. J Clin Endocrinol Metab. 2010;95:3437-45.

42. Heneweer C, Schmidt M, Denker H-W, Thie M. Molecular mechanisms in uterine epithelium during trophoblast binding: the role of small GTPase RhoA in human uterine Ishikawa cells. J Exp Clin Assist Reprod. 2005;2:4.
43. Mohamed OA, Jonnaert M, Labelle-Dumais C, Kuroda K, Clarke HJ, Dufort D. Uterine Wnt/ $\beta$-catenin signaling is required for implantation. Proc Natl Acad Sci U S A. 2005;102:8579-84.

44. Bartel DP. MicroRNAs: genomics, biogenesis, mechanism, and function. Cell. 2004;116:281-97.

45. Ji Q, Xu X, Song Q, Xu Y, Tai Y, Goodman SB, Bi W, Xu M, Jiao S, Maloney WJ: miR-223-3p inhibits human osteosarcoma metastasis and progression by directly targeting CDH6. Mol Ther 2018, 26:1299-1312.

46. Dong $X$, Sui C, Huang K, Wang L, Hu D, Xiong T, Wang R, Zhang H. MicroRNA-223-3p suppresses leukemia inhibitory factor expression and pinopodes formation during embryo implantation in mice. Am J Transl Res. 2016;8:1155

47. Marwood M, Visser K, Salamonsen L, Dimitriadis E. Interleukin-11 and leukemia inhibitory factor regulate the adhesion of endometrial epithelial cells: implications in fertility regulation. Endocrinology. 2009;150:2915-23.

48. White CA, Zhang J-G, Salamonsen LA, Baca M, Fairlie WD, Metcalf D, Nicola NA, Robb L, Dimitriadis E. Blocking LIF action in the uterus by using a PEGylated antagonist prevents implantation: a nonhormonal contraceptive strategy. Proc Natl Acad Sci U S A. 2007;104:19357-62.

49. Shariati MBH, Niknafs B, Seghinsara AM, Shokrzadeh N, Alivand MR. Administration of dexamethasone disrupts endometrial receptivity by alteration of expression of miRNA 223, 200a, LIF, Muc1, SGK1, and ENaC via the ERK1/2-mTOR pathway. J Cell Physiol. 2019;234:19629-39.

50. Takamura M, Zhou W, Rombauts L, Dimitriadis EJBor: The long noncoding RNA PTENP1 regulates human endometrial epithelial adhesive capacity in vitro: implications in infertility. 2019.

51. Li F, Zhang M, Zhang Y, Liu T, Qu X. GnRH analogues may increase endometrial Hoxa10 promoter methylation and affect endometrial receptivity. Mol Med Rep. 2015;11:509-14.

\section{Publisher's Note}

Springer Nature remains neutral with regard to jurisdictional claims in published maps and institutional affiliations.
Ready to submit your research? Choose BMC and benefit from:

- fast, convenient online submission

- thorough peer review by experienced researchers in your field

- rapid publication on acceptance

- support for research data, including large and complex data types

- gold Open Access which fosters wider collaboration and increased citations

- maximum visibility for your research: over $100 \mathrm{M}$ website views per year

At $\mathrm{BMC}$, research is always in progress.

Learn more biomedcentral.com/submissions 